\title{
Brasil e Alemanha: Imigração e Imperialismo (1871-1918)
}

\author{
Brazil and Germany: Immigration and Imperialism (1871-1918) \\ Brasil y Alemania: Inmigración y Imperialismo (1871-1918)
}

Wilson Maske*

\section{Resumo}

O presente estudo tem o objetivo de mapear e avaliar os interesses e consequências do estabelecimento das relações econômicas entre Brasil e Alemanha, considerando a inserção de imigrantes alemães no Brasil e seus reflexos econômicos. O método utilizado para verificar o estabelecimento de relações entre Brasil e Alemanha foi a Teoria das Forças Profundas, desenvolvida por Pierre Renouvin e Jean-Baptiste Duroselle. Essa teoria que considera as tendências e características de longa duração como influência nas relações externas de uma determinada unidade estatal, considerando os interesses econômicos, entre outros, como uma dessas forças. Buscou-se, então, analisar Brasil e Alemanha como dois atores nesse quadro de mudanças trazidas pelo capitalismo e pela industrialização crescentes, a fim de compreender quais os resultados da imigração para o Brasil e se a Alemanha consolidou seus interesses imperialistas com a inserção desses imigrantes.

Palavras-chave: Imigração Alemã ao Brasil. Imperialismo Alemão. Relações exteriores do Brasil.

\section{Introdução}

Os objetivos deste estudo relacionam-se com os interesses de investigar o estabelecimento das relações entre Brasil e Alemanha, verificando a relevância do fluxo imigratório alemão para o Brasil, assim

* Doutor em história pela UFPR (2004), professor
titular de história contemporânea na PUCPR.
Estuda temas ligados à imigração, movimen-
tos de extrema-direita, política externa bra-
sileira e história das relações internacionais.
E-mail: wilson.maske@uol.com.br.

Recebido em 05/07/2013 Aprovado em 06/08/2013 http://dx.doi.org/10.5335/hdtv.14n.1.4174 
como os reflexos das relações políticas e comerciais estabelecidas entre os dois países. Avaliar que papel o Brasil representou no desenvolvimento do imperialismo alemão no período de 1871 a 1918, destacando os interesses econômicos e geopolíticos, e em especial, o papel dos imigrantes alemães e de seus descendentes no sul do Brasil.

As relações entre Brasil e Alemanha foram muito além do café, principal produto brasileiro durante o final do Segundo Reinado e durante a Primeira República em termos de comércio internacional, considerando que as relações diplomáticas estabelecidas entre países envolvem motivações políticas, culturais, ideológicas e interesses econômicos. Esses interesses estão inseridos em um contexto de mudanças estruturais ocorridas no Brasil, como a do regime político para a República em 1889. O Brasil, apesar de sua importância na América do Sul, era um ator secundário no quadro mundial, fornecendo matérias-primas como café, açúcar, tabaco, borracha e outros produtos básicos, gravitando entre a Grã-Bretanha e os Estados Unidos. Dessa forma, a diplomacia brasileira esforçou-se para divulgar tais produtos na Europa, visando às exportações, à atração de imigrantes e de capitais que promovessem o desenvolvimento do país.

Ao analisar a reorientação da política externa brasileira com o advento da República, notou-se que houve, por parte do governo brasileiro, principalmente com a gestão de Rio Branco, um grande esforço para colocar o Brasil em uma posição mais representativa no quadro internacional, assim como, fugir do predomínio da Grã-Bretanha, que exercia sobre o Brasil grande influência econômica.
Nesse contexto, a americanização das relações internacionais mostrava-se vantajosa para o Brasil, pois, além de encontrar mercado para seus produtos de exportação, recebia benefícios políticos em sua relação com os Estados Unidos. Com uma política exterior de viés pacifista, o Brasil, igualmente, teve a possibilidade de estabelecer ou de ampliar suas relações com outros países, como a Alemanha, com quem passou a promover o comércio de importação e exportação, e de atrair mão de obra imigrante, algo que, se pensava, poderia trazer grandes transformações à economia nacional, mas também fazer parte do projeto de modernização do país com o advento do regime republicano.

$\mathrm{Na}$ Alemanha, inicialmente, o Zollverein, em 1834, foi a união aduaneira dos estados alemães com exclusão da Áustria, que demonstrava a aceleração da Segunda Revolução Industrial nos territórios de língua alemã, situados na Europa Central, em especial nas regiões do Ruhr, do Sarre e da Saxônia. As dificuldades de unificar o país estenderam-se até a década de 1860, quando o Reino da Prússia passou a liderar o movimento de unificação, por meio de estratégia militar. Maria Luisa Renaux Hering oferece-nos um panorama dessa situação:

O processo de unificação do reino alemão favoreceu o desenvolvimento econômico e a revolução industrial alemã, que se iniciou propriamente em 1850 e que teve nos anos subseqüentes à unificação, conhecidos como Gründerjahre, anos de fundação, o seu boom. Nesses anos, a emigração foi desmotivada - o Estado necessitava de mão-de-obra para sua indústria pesada e para construção de ferrovias. A burocratização e a militarização da vida pública, mais uma política interna imperialista, jun- 
taram na Alemanha do II Reich nacionalismo, militarismo e monarquia e a tornaram economicamente a nação mais poderosa da Europa. O próximo Kaiser, Guilherme II, ambicionando tomar as rédeas do Estado, exigiu a demissão de Otto von Bismarck. Seu governo caracterizou-se por uma linha política mais conciliatória e assegurou a posição da Alemanha como Weltmachtstellung, potência mundial (1995, p. 32).

Com a saída de Bismarck, em 1890, a Alemanha guilhermina passou então a desenvolver uma política externa ambiciosa, especialmente voltada ao imperialismo. Contudo, não dispunha de espaço econômico suficiente para a dimensão que o desenvolvimento de sua força produtiva alcançou. Houve, assim, a necessidade por parte da elite política e econômica alemã de dilatar as áreas de influência do capitalismo alemão, para obter fontes de matérias-primas, mercados para vendas de manufaturas e inversão de capitais acumulados. Nisso, incluimos o esforço em obter melhores mercados consumidores para os produtos industriais alemães, colônias que pudessem também oferecer fontes de matérias-primas e locais para o investimento dos capitais auferidos com o desenvolvimento industrial. A Europa Oriental, a Ásia, a América Latina e notadamente, o Brasil, figuravam, a partir de então, como áreas de interesse aos alemães. Além disso, o Brasil, em especial, em função da grande presença de imigrantes alemães, representava uma área de grande interesse para a diplomacia e para os interesses econômicos do Império Alemão.

Por sua vez, o Brasil tinha motivos em querer ampliar seu escopo de parceiros internacionais, tanto para fomentar o mercado de produtos tropicais, quanto para fornecer mão de obra para lavouras de café, ocupar espaços demográficos vazios, além de formar pequenos proprietários agrícolas que abasteceriam as grandes cidades, construindo juntamente obras públicas. As colônias eram criadas por iniciativa de particulares ou dos governos, porém, existiam divergências entre a política imigratória do poder central e as reações tomadas pelos governos das províncias.

\section{A imigração como uma empresa}

De acordo com Willems (1980), o povoamento sistemático do Brasil meridional com imigrantes germânicos iniciou-se em 1824. Os imigrantes germânicos abandonaram uma cultura em plena mudança, com ritmos variados, em que a sociedade rural secularizava-se, e as comunidades vinham articulando-se aos mercados urbanos no compasso de uma industrialização crescente. Portanto, a imigração esteve ligada a motivos sociais, políticos e religiosos, mas também a uma forma de resolver dificuldades econômicas, prevenindo ou modificando situações indesejáveis.

Um dos fatores motivadores da colonização privada era o comércio de terras, fundadas com capital estrangeiro ou brasileiro, organizadas individual ou comunitariamente, as terras eram vendidas pelo menor preço possível, adotando o sistema de colonização adequado a seus desígnios econômicos. Os imigrantes alemães trouxeram um padrão econômico que influiu, decisivamente, sobre a cultura do Brasil meridional, pois eram, em geral, camponeses habituados com a exploração capitalista das terras, produzindo não 
apenas para a própria subsistência, mas também para atender às exigências de um mercado em crescente demanda por variados produtos, em especial os ligados à produção de alimentos, laticínios e embutidos. Os imigrantes também representavam uma considerável mão de obra urbana, como trabalhadores relacionados a ofícios necessários ao desenvolvimento das cidades no Brasil. Trabalhavam como marceneiros, alfaiates, pedreiros, pintores, padeiros, cervejeiros e em outras atividades, que, muitas vezes, eram associadas ao trabalho agrícola. Além disso, apareciam como comerciantes de atacado e varejo, profissionais liberais e empreendedores, em especial como industriais.

No tocante às relações entre Alemanha e Brasil, as conexões eram antigas e precederam a unificação alemã de 1871, quando vários estados alemães, como a Prússia, a Áustria e a Baviera, já mantinham importantes conexões com o país. Descontando a presença de alemães no Brasil desde o período colonial (Hans Staden, Erasmo Schetz, João Maurício de Nassau-Siegen, Barão de Eschwege, entre outros), as relações diplomáticas e comerciais foram, pela primeira vez, estabelecidas em 1827, quando as cidades-livres de Hamburgo, Bremen e Lübeck reconheceram o Império do Brasil, seguidas pelo Reino da Prússia. Entre 1827 e 1871, houve um intenso relacionamento entre os Estados Alemães e o Brasil, relacionados a uma infinidade de áreas de interesse, desde o comércio de cacau e madeiras, até o agenciamento de imigrantes para o povoamento e provimento de mão de obra no Brasil. Havia, pois, uma vasta gama de proveitos que motivaram as relações entre o Brasil e a Alemanha.
Para ser possível analisar e compreender os fatores que levaram ao estabelecimento e a intensificação das relações entre Brasil e Alemanha, consideramos a Teoria das Forças Profundas, elaborada por Pierre Renouvin e Jean-Batiste Duroselle, que avaliam

[...] as forças profundas são aqueles eventos, tendências e características de longa duração que influenciam ou determinam as relações externas de uma determinada unidade estatal. Essas forças profundas podem estar relacionadas com condições geográficas do território do estado, com suas características demográficas, com seus interesses econômicos, com o jogo de sua política interna, com a questão da psicologia coletiva, com o nacionalismo, com a opinião pública, com a influência da mídia e seu controle, com influência das religiões e dos líderes religiosos, com o papel e a ação do estadista, entre outras. Nessas condicionantes é que poderemos encontrar os fatores que determinam as relações internacionais e que servem de interpretação e de análise para a historiografia das relações internacionais (RENOUVIN \& DUROSELLE, 1967, p. 15).

Partindo dessa teoria, considera-se que os imigrantes tornaram-se um importante fator econômico tanto para a Alemanha pela importância atribuída ao papel dos imigrantes alemães vistos como "porta de entrada" para produtos industriais no Brasil, assim como elementos políticos facilitadores nas negociações com o governo brasileiro e com os governos regionais. No Brasil, os imigrantes eram vistos como importante fonte de mão-de-obra e, posteriormente elemento impulsionador para a indústria, com inovações técnicas e nova mentalidade, trazendo, consequente, progresso econômico nas regiões em que se estabeleceram. 
As forças profundas fizeram-se presentes também na formação da psicologia coletiva alemã com a consolidação do nacionalismo e do imperialismo, interesses econômicos que motivaram o governo alemão e as decisões do chefe de estado, considerando as ambições do Kaiser Guilherme II, a opinião pública e sua manipulação através das propagandas de emigração e dos grupos de pressão. Esses exerciam influência sobre as decisões do chefe de estado, como representantes da burguesia, empresários, proprietários rurais e políticos alemães que lucrariam com a emigração, ficando evidente nos escritos de Klaus Richter que analisou fontes alemãs em Hamburgo:

[...] adeptos do imperialismo e nacionalismo da época consideravam de interesse nacional que pela emigração os emigrantes não perdessem a sua etnia, cultura, língua e nacionalidade, mas, sim, formassem poderosos quistos étnicos no além-mar. Para tal fim, recomendavam que fossem fundadas colônias agrícolas em regiões que:

Sendo pouco habitadas pelos nativos e possuindo condições climáticas vantajosas, favorecessem uma imigração alemã em grande escala com boas possibilidades de desenvolvimento.

Pelo fato de a população nativa ser de "raça inferior", garantissem que a etnia, cultura, língua e nacionalidade dos imigrantes ficariam preservadas. A longo prazo, fornecessem matérias-primas para a Alemanha; e, no início não desenvolvessem indústria própria, dependendo, portanto, da importação de produtos industriais da Alemanha (RICHTER, 1986, p. 13).

Ainda de acordo com Richter, em 1891, segundo estimativa do Ministério das Relações Exteriores Alemão, viviam cerca de 200 mil pessoas de língua alemã no Sul do Brasil.
Entusiastas pela fundação de colônias agrárias alemãs demonstravam suas intenções:

Um deles, Karl Ballod, achava em 1899, que seria possível estabelecer de 500 a $750 \mathrm{mil}$ famílias de pequenos camponeses alemães no sul do Brasil. Um outro, Robert Jannasch, em 1902 calculava que seria possível estabelecer 5000 a 7500 imigrantes por ano, dentro de 16 a 20 anos, já estariam vivendo naquelas regiões brasileiras, 100 mil colonos alemães, os quais então, comprariam artigos importados da Alemanha, num valor de aproximadamente, 10 milhões de marcos. Eis aí, a importância que muitos na época estavam atribuindo à colonização alemã no Brasil meridional para a indústria e comercio da época. Segundo eles, os colonos alemães até então introduzidos lá, já estariam formando uma classe dominante na economia sul-brasileira. Esperava-se que ele, embora cidadãos brasileiros ficassem economicamente vinculados ao império alemão (RICHTER, 1986, p. 14).

Contudo, apesar dessas intenções, muitos dos planos não se mostravam viáveis por uma série de condições. A grande maioria dos alemães estabelecidos no Brasil aceitava a soberania nacional e, seus filhos se reconheciam como cidadãos brasileiros, sem que o domínio econômico alemão fosse imposto, mas que se preservassem os valores alemães. Melhor dizendo: os imigrantes valorizavam sua origem, mas sabiam que estavam em outro país e queriam integrar-se às condições locais e não criar entraves com as autoridades brasileiras. Além disso, existiam divergências entre imperialistas alemães, ministros de relações exteriores e ministros do comércio na Alemanha. Esse último considerava urgente a exploração de novos mercados transatlânticos e mercados consumidores de produtos alemães. Por ou- 
tro lado, o ministro do interior não estava interessado na emigração, pelo receio de falta de mão de obra na Alemanha, numa época de intensa industrialização. Assim, vários planos de imigração e de colonização com colonos alemães não foram levados adiante:

Ao mesmo tempo, o embaixador alemão no Brasil, Krauel, visitara as áreas de colonização teuta. Em 1895, compilou um relatório extremamente positivo sobre a situação dos alemães e seus descendentes no sul do país. Teriam alcançado posição econômica fortíssima em Santa Catarina, dominando o comércio de importação. Joinville seria uma cidade alemã. Mesmo assim, Krauel lamentava que os teuto-brasileiros ainda não exercessem grande influência política e que, devido ao numero insuficiente de imigrantes, até então não teriam conseguido penetrar a região de forma favorável aos interesses alemães (RICHTER, 1986, p. 17).

\section{As sociedades colonizadoras}

Por trás da iniciativa particular de recrutamento de emigrantes, estavam os interesses das companhias colonizadoras. Havia atenção na exploração de novas áreas, movimentação de pessoas e venda de propriedades fazendo da imigração uma empresa e dos imigrantes uma espécie de "mercadoria". Havia competição entre as agências que ganhavam por imigrante embarcado, utilizavam-se então de propagandas. A cidade de Hamburgo era um importante porto de embarque de imigrantes, não apenas de alemães, mas também de indivíduos originários da Europa Oriental, como poloneses, judeus, russos, interessados em uma vida melhor na América.
Segundo Renaux (1995), a imigração teve papel decisivo no florescimento da navegação alemã. Todas as firmas marítimas importadoras tinham sua quota nos negócios imigratórios. $\mathrm{O}$ desenvolvimento das companhias Hapag e Norddeutscher Lloyd estava relacionado à imigração. $\mathrm{O}$ recrutamento de passageiros virou uma cadeia de negócios, à qual os imigrantes tinham de se sujeitar. As atividades das sociedades colonizadoras estavam ligadas a interesses econômicos alemães, apoiados no capitalismo comercial liberal. Como citado anteriormente, desde 1827 já existia entre o Brasil e a Cidade Livre de Hamburgo um tratado de comércio e navegação fechado também com as cidades de Bremen e Lübeck, visando ampliar as relações econômicas entre brasileiros e hanseáticos. Os empresários hamburgueses, sabendo das possibilidades de negócios com a imigração, e em apoio aos interesses brasileiros, fundaram a Sociedade de Fomento à Emigração Alemã para o Brasil, posteriormente transformada na Sociedade de Fomento à Emigração Alemã para o Brasil.

\section{As colônias alemãs e seus reflexos econômicos no Brasil}

Por iniciativa particular ou governamental, formaram-se no Brasil vários tipos de colônias, como as de companhias de colonização e as colônias surgidas pela iniciativa privada de pessoas físicas. Conforme Pinheiro e Holanda (2006, p. 107-108), a posição do governo brasileiro frente aos problemas de imigração e de colonização dependia, em grande parte, dos recursos disponíveis 
e também da política econômico-financeira adotada. Um mês após a proclamação da República, o governo provisório, atendendo a interesses variados ligados à imigração, decretou que fossem considerados cidadãos brasileiros todos os estrangeiros aqui residentes em 15 de novembro de 1889 e os que tivessem residência no país por dois anos. $\mathrm{O}$ decreto de janeiro de 1890 procurava atrair o "proletário agrícola nacional" para a tarefa de colonização e chamava a atenção para a necessidade de povoamento das fronteiras.

Pela lei orçamentária de 1894, a colonização e imigração passam a ser atribuições dos Estados, apesar de que as províncias do Império já haviam debatido intensamente o tema. Uma vez estabelecidos, os imigrantes alemães interferiam fortemente no processo econômico brasileiro, especialmente desenvolvendo indústrias próprias, importando maquinismos e promovendo novas técnicas, além do comércio, fator propulsor de avanço econômico no Brasil. Conforme Oberacker (1968), os empreendimentos industriais, frequentemente associavam-se a casas de importação e exportação, as quais passaram a adotar novos rumos de comércio no país e assim proporcionaram outras possibilidades de negócios com os alemães. Logo, a participação econômica de empresários ligados ao comércio de exportação e importação tornou-se fundamental para os Estados meridionais do Brasil e para a formação de um segmento empresarial num mundo burguês em expansão.

Notamos que a iniciativa privada fomentou o surgimento de uma indústria diversificada para os padrões da época, concentrando-se no Rio Grande do Sul, no
Paraná e em Santa Catarina. Destarte, é possível pontuar regiões específicas de empreendimentos empresariais como o vale do Itajaí, em Santa Catarina, por exemplo, foco de estudo da historiadora Maria Luiza Renaux Hering, citada anteriormente.

Conforme Hering (1987, p. 13), as empresas têxteis do Vale do Itajaí caracterizaram-se pelo investimento exclusivo de recursos particulares, provenientes dos próprios empreendedores, o que os tornou economicamente independentes e com determinado grau de estabilidade. Constata-se sua independência em relação ao governo, a ausência de subsídios e favores (isenções fiscais, licenças especiais) que as empresas mais próximas dos grandes centros recebiam e em relação às instituições bancárias, inexistentes localmente. Decorre dessa autossuficiência e solidez a capacidade de manter-se no mercado e de resistir a conjunturas difíceis.

Baseando-se ainda nos estudos de Hering, houve uma integração do vale do Itajaí ao quadro da industrialização brasileira, na forma de pequenas e médias empresas familiares, independentes em relação a instituições financeiras, possuindo mão de obra qualificada e treinada no ambiente do artesanato e da revolução industrial alemã, trazendo a valorização da qualidade do produto final e do cooperativismo desenvolvido nas dificuldades surgidas nos primeiros anos da imigração. Essas atitudes prolongaram-se nas relações empresariais que se transformaram em empreendimentos sólidos, expandindo-se nacionalmente de forma autônoma: 
Se existiu algum fator de ligação externa, como muitos o querem, este não se teria ligado através das regiões economicamente mais desenvolvidas do país, mas sim pela expansão da economia catarinense para os projetos internacionais. Tratava-se de relações pessoais no intercâmbio entre os comerciantes alemães e os imigrantes da mesma origem (HERING, 1987, p. 13).

Logo, mapeando tais reflexos para economia brasileira e pontuando espacialmente a localização de empreendimentos alemães, percebemos casos específicos e diferenciados de desenvolvimento econômico, principalmente na região Sul do Brasil. Com desenvolvimento próprio, de acordo com recursos disponíveis e como forma de resposta a problemas que se apresentaram para os imigrantes, os quais, através de muito trabalho e de suas iniciativas, transformaram suas fábricas em grandes empreendimentos industriais.

Como já explicitado, o objetivo do presente estudo é analisar os reflexos econômicos da imigração alemã para o Brasil e o jogo de interesses que nortearam sua relação com a Alemanha. Com esse intuito, utilizamos a teoria das forças profundas, desenvolvida por Renouvin e Duroselle, o que propiciou perceber que a imigração de alemães para o Brasil foi um fator que auxiliou, em determinada medida, ao processo de desenvolvimento industrial no Sul do país. Considera-se, então, um quadro complexo que envolve interesses nacionais influenciados por diferentes grupos de pressão no seio do estado. A Alemanha, no período analisado, preparava-se para desempenhar um papel preponderante no quadro internacional, levando em consideração a força do nacionalismo e da influência da Liga Pangermânica, comum aos grupos políticos que chegaram ao poder logo após a ascensão ao trono imperial do príncipe Guilherme, neto de Guilherme I, em 1888. Grandes grupos econômicos alemães, ligados aos negócios internacionais, começaram a pressionar o novo imperador a assumir uma postura mais agressiva no cenário internacional, a fim de ampliar o poderio econômico do país e fomentar o expansionismo do capitalismo alemão não apenas na Europa, mas, no mundo, por meio de uma política mundial (Weltpolitik).

Nessa perspectiva, o Brasil interessou à Alemanha, dados os grandes empreendimentos imigratórios, também bastante lucrativos para donos de agências de imigração, cujos interesses, tanto públicos quanto privados, motivaram empreendedores alemães a estabelecer relações com o governo brasileiro. As várias formas de colonização, ainda que algumas não tenham alcançado o êxito esperado, serviram para contemplar, ao menos em parte, os propósitos de ambos os países.

Assim, principalmente, com base na leitura de Richter, pode-se avaliar que as atividades de colonização não foram financeiramente vantajosas para os alemães. De início, a Sociedade Colonizadora Hanseática, apoiada por capitalistas lucrava com o crescimento da frota comercial em virtude da imigração, assim como os comerciantes de cidades alemãs também lucravam, firmando contratos com governos de Estados brasileiros para a instalação de colônias. Nesse sentido, logo surgiram empreendimentos coloniais pela iniciativa privada de particulares, como o exemplo do Dr. Hermann Blumenau. Foram também criadas colônias de parceria através da iniciativa de 
latifundiários que subdividiram suas terras para fins de colonização. É necessário considerar que muitos desses empreendimentos fracassaram e muitos colonos enfrentaram situações adversas, sendo enganados pela propaganda que colocava a América como um lugar ideal. Por vezes, os programas de colonização foram pouco eficientes e não alcançaram os resultados esperados.

$\mathrm{Na}$ perspectiva brasileira em tais relações,considera-se importante a avaliação de Klaus Richter de que, pelo ponto de vista financeiro, atividades como as da Sociedade Colonizadora Hanseática perderam o capital investido, principalmente considerando os ambiciosos interesses dos círculos imperialistas e nacionalistas alemães, de criar vastos quistos étnicos no Sul do Brasil. No entanto, através dessas sociedades colonizadoras várias regiões foram colonizadas e tiveram a médio e longo prazo efeitos econômicos positivos sobre o quadro econômico das regiões em que se instalaram, no sentido de povoamento e de ocupação do território. De acordo com a leitura do pastor Fugmann, observador atento da imigração alemã para o Paraná:

A contribuição dos alemães na economia e cultura do Paraná foi significativa. Mesmo que não possamos apresentar dados estatísticos específicos do passado distante, as fábricas, as casas comerciais, que ao longo do tempo, a partir de um começo humilde, se desenvolveram, bem como a história desse desenvolvimento, isoladamente ou como um todo, constituem uma parcela da história econômica paranaense (FUGMANN, 2008, p. 159).

Dessa mesma forma, Hering, estudando o desenvolvimento econômico do Vale do Itajaí, avalia que, nessa região, a fase rural foi superada após os primeiros trinta anos desde a fundação das colônias de Blumenau e de Brusque, ocorridas na década de 1850. O modelo colonial não havia se esgotado, apenas delinearam-se na época, os traços de uma nova atividade, a agricultura fomentou a indústria de beneficiamento, surgindo fábricas conhecidas em todo o país. O progresso do comércio acumulou capitais, investidos na experiência artesanal e fabril dos imigrantes alemães e de seus descendentes teuto-brasileiros. A indústria têxtil criada tornou-se a identidade econômica da região.

Durante a Primeira Guerra Mundial, a situação industrial do Brasil modificou-se consideravelmente. Nessas ocasiões, a importação de mercadorias de determinados países, em especial dos Impérios Centrais, chegou a ser sustada. Logo, o exterior já não podia satisfazer nossas necessidades de produtos industrializados. Assim, as indústrias aqui existentes foram incentivadas pela demanda a expandir-se e, os empresários, a ampliar suas instalações. Foi, então, da iniciativa particular, que surge uma indústria diversificada, a indústria artesanal, em sua maioria, foi criada por imigrantes de diversas origens e por famílias brasileiras enraizadas no país. Nos três Estados do extremo sul, os alemães lideravam em relação à industrialização, incorporando-se à indústria nacional e estimulando a economia brasileira, indo ao encontro das necessidades apresentadas naquele período. 


\section{Considerações finais}

Através dos resultados obtidos, foi possível mapear os interesses alemães e brasileiros no estabelecimento de relações diplomáticas que envolveram questões complexas como pressões internas, necessidades econômicas e ideologias, como o imperialismo e o nacionalismo. Nesse jogo de poder, entre divergências e congruências de interesses, histórias de sucessos e de fracassos, foi possível avaliar o processo da imigração alemã para o Brasil e seu papel nas relações entre um grande país da América do Sul e uma potência imperialista européia em ascensão. A imigração alemã para o Brasil esteve ligada às rápidas mudanças políticas e econômicas ocorridas na Alemanha e no Brasil. Os imigrantes representaram um sentido de mudança no Brasil. Diferentes tipos de propriedade, de visão frente ao trabalho e de mudança social foram introduzidos e tornaram-se perenes nas regiões por eles colonizadas. Esses imigrantes, no entanto, em certa medida, fugiram do papel de instrumentos do imperialismo alemão, uma vez que o lugar de intermediários ocupado nas relações entre o Brasil e a Alemanha não era realmente de seu interesse. A integração à realidade social, econômica e política brasileira era prioridade para as comunidades imigrantes e isso desafiava sua ligação com a Alemanha, ainda que estes se sentissem emocionalmente ligados à Europa. Mas isso não impedia que vissem com clareza que seu destino e futuro, como imigrantes, estavam indelevelmente ligados ao Brasil e não mais à Alemanha.

\section{Abstract}

The present study aims to map and assess the interests and consequences of the establishment of economic relations between Brazil and Germany considering the inclusion of German immigrants in Brazil and its economical effect. The used method to provide an evaluation of the relations between Brazil and Germany was the Theory of Deep Forces developed by French historians Pierre and Jean-Baptiste Renouvin Duroselle, which takes into account trends and characteristics of long duration which influence or determine external relations of a particular unit considering state economic interests as one of these forces, we sought then analyze Brazil and Germany as two actors in this context of change, when capitalism and industrialization were rising, trying to understand what the results of immigration to Brazil and Germany consolidated its imperialist interests in the integration of these immigrants.

Keywords: German Immigration to Brazil. German Imperialism. Brazilian Foreign Relations.

\section{Resumen}

El presente estudio tiene como objetivo describir y evaluar los intereses y las consecuencias del establecimiento de las relaciones económicas entre Brasil y Alemania están considerando la inclusión de los inmigrantes alemanes en Brasil y sus consecuencias económicas. El método utilizado para mapear y evaluar el establecimiento de las 
relaciones entre Brasil y Alemania fue la Teoría de las Fuerzas Profundas desarrollada por Pierre y Jean-Baptiste Renouvin Duroselle, que tiene en las tendencias y características de larga duración cuenta que influyen o determinan las relaciones exteriores estado de una unidad particular, teniendo en cuenta los intereses económicos, entre otros, ya que estas fuerzas. Hemos tratado de analizar a continuación, Brasil y Alemania, dos actores en este contexto de cambios provocados por el capitalismo y el aumento de la industrialización con el fin de entender lo que los resultados de la inmigración a Brasil y Alemania consolidan sus intereses imperialistas en la integración de estos inmigrantes.

Palabras clave: Inmigración alemana en Brasil. Imperialismo alemán. Relaciones exteriores de Brasil.

\section{Referências}

FOUQUET, C. O imigrante alemão e seus descendentes no Brasil 1808-1824-1974. São Paulo: Instituto Hans Staden; São Leopoldo: Federação dos Centros Culturais 25 de Julho, 1974.

FULBROOK, M. História concisa da Alemanha. São Paulo: EDIPRO, 2012.

FUGMANN, W. Os alemães no Paraná. Ponta Grossa: Ed. UEPG, 2008.

HERING, M. L. R. Colonização e indústria no Vale do Itajaí: o modelo catarinense de desenvolvimento. Blumenau: Fundação Universidade Regional de Blumenau, 1987.

KLEIN, H. S. Migração internacional na história das Américas. In: FAUSTO, B. (Org.) Fazer a América. São Paulo: Ed. da Universidade de São Paulo, 2000.
MENEZES, A. M. F. Utopia, imigração e a colônia alemã de Una, Bahia no contexto histórico. Textos de História: Revista do Programa de Pós- graduação em História da UNB. Brasília: UNB, vol. 16, n. 2, 2008.

RENOUVIN, P.; DUROSELLE, J.-B. Introdução à história das relações internacionais. São Paulo: Difusão Europeia do Livro, 1967.

RICHTER, K. A sociedade colonizadora hanseática de 1897 e a colonização de Joinvile e Blumenau. Florianópolis: Ed. da UFSC, 1986.

SEYFERTH, G. A Colonização alemã no Brasil: etnicidade e conflito. In: FAUSTO, B. (Org.) Fazer a América. São Paulo: Ed. da Universidade de São Paulo, 2000.

OBERACKER JUNIOR, C. H. A contribuição teuta na formação da nação brasileira. Rio de Janeiro: Presença, 1968.

WILLEMS, E. A aculturação dos alemães no Brasil: estudo antropológico dos imigrantes alemães e seus descendentes no Brasil. 2. ed. rev. e ampl. São Paulo: Nacional, 1980. 